\title{
Physical Examination Severity
}

National Cancer Institute

\section{Source}

National Cancer Institute. Physical Examination Severity. NCI Thesaurus. Code C83357.

The degree of something undesirable as determined by physical assessment. 